\title{
Polyvinyl Alcohol Polymer Functionalized Graphene Oxide Decorated with Gadolinium Oxide for Sequestration of Radionuclides from Aqueous Medium: Characterization, Mechanism, and Environmental Feasibility Studies
}

\author{
Lakshmi Prasanna Lingamdinne ${ }^{1}$ (D) Janardhan Reddy Koduru ${ }^{1, *(D)}$, Yoon-Young Chang ${ }^{1}$, Mu. Naushad $^{2}$ (D) \\ and Jae-Kyu Yang ${ }^{1, *}$ \\ 1 Department of Environmental Engineering, Kwangwoon University, Seoul 01897, Korea; \\ swethasiri86@gmail.com (L.P.L.); yychang@kw.ac.kr (Y.-Y.C.) \\ 2 Department of Chemistry, College of Science, King Saud University, Riyadh 11451, Saudi Arabia; \\ mnaushad@ksu.edu.sa \\ * Correspondence: reddyjchem@gmail.com (J.R.K.); jkyang@kw.ac.kr (J.-K.Y.)
}

Citation: Lingamdinne, L.P.; Koduru, J.R.; Chang, Y.-Y.; Naushad, M.; Yang, J.-K. Polyvinyl Alcohol Polymer Functionalized Graphene Oxide Decorated with Gadolinium Oxide for Sequestration of Radionuclides from Aqueous Medium: Characterization, Mechanism, and Environmental Feasibility Studies. Polymers 2021, 13, 3835. https:// doi.org/10.3390/polym13213835

Academic Editor: Alfredo Cassano

Received: 16 October 2021

Accepted: 4 November 2021

Published: 6 November 2021

Publisher's Note: MDPI stays neutral with regard to jurisdictional claims in published maps and institutional affiliations.

Copyright: (c) 2021 by the authors. Licensee MDPI, Basel, Switzerland. This article is an open access article distributed under the terms and conditions of the Creative Commons Attribution (CC BY) license (https:/ / creativecommons.org/licenses/by/ $4.0 /)$.

\begin{abstract}
Uranium (U(VI)) and thorium (Th(IV)) ions produced by the nuclear and mining industries cause water pollution, thereby harming the environment and human health. In this study, gadolinium oxide-decorated polyvinyl alcohol-graphene oxide composite (PGO-Gd) was developed using a simple hydrothermal process to treat $\mathrm{U}(\mathrm{VI})$ and $\mathrm{Th}(\mathrm{IV})$ ions in water. The developed material was structurally characterized by highly advanced spectroscopy and microscopy techniques. The effects of $\mathrm{pH}$, equilibration time and temperature on both radionuclides (U(VI) and Th(IV)) adsorption by PGO-Gd were examined. The PGO-Gd composite adsorbed both metal ions satisfactorily, with adsorption capacities of 427.50 and $455.0 \mathrm{mg} \mathrm{g}^{-1}$ at $\mathrm{pH} 4.0$, respectively. The adsorption properties of both metal ions were found to be compatible with the Langmuir and pseudo-second-order kinetic models. Additionally, based on the thermodynamic characteristics, the adsorption was endothermic and spontaneous. Furthermore, the environmental viability of PGO-Gd and its application was demonstrated by studying its reusability in treating spiked surface water. PGO-Gd shows promise as an adsorbent in effectively removing both radionuclides from aqueous solutions.
\end{abstract}

Keywords: PVA-GO-Gd composite; characterization; polyvinyl alcohol polymer; graphene oxide; gadolinium oxide; uranium; thorium; water treatment; adsorption mechanism

\section{Introduction}

Uranium and thorium ions pollute groundwater and cause environmental and human health problems [1]. These radioactive wastes are produced as a result of nuclear fuel manufacturing and a range of industrial operations, including nuclear power stations, mining, nuclear arms, nuclear armament and laboratories dealing with radioactive elements. Radioactive ions may harm biological systems, and cause kidney damage, toxic hepatitis, damage to the histopathological system, skin corrosion and possibly cancer [2-4]. In addition, radionuclides (nuclear fuels) must be recovered from waste, which reduces the demand for nuclear power generation. Thus, a common and efficient method in treating radioactive-contaminated water is adsorption.

Graphene is a one-atom thick hexagonal sheet made up of $\mathrm{sp}^{2}$ hybridized carbon atoms tightly packed into a 2D honeycomb structure. It has great thermal conductivity, exceptional mechanical strength, and good electrical conductivity [5,6]. Graphene oxide (GO) is an oxidized form of graphene having a basal plane that is primarily changed with epoxide and hydroxyl groups, with carboxyl and carbonyl groups at the edges. Moreover, GO and GO-based materials are widely used in treating wastewater contaminated with heavy metals, radionuclides, and organic pollutants [7-10]. However, the real applicability 
of these materials in treating specific pollutants is limited because of their low functionality, high dispersibility, high aggregation, complex installation, and other physicochemical factors. However, surface modification of carbon materials with other materials leads to the enhancing of its stability feasibility for various sustainable applications [11,12]. For instance, the recent research on graphene-based polymer nanocomposites has opened a new avenue of study in the field of polymer nanocomposites [13]. Their properties are strongly connected to their nanostructures; homogeneous dispersion of nanocomposites and the exclusion of coalescence in the polymer matrices are critical for improving their properties [14]. Poly (vinyl alcohol) (PVA), a synthetic polymer derived from the parent polymer poly (vinyl acetate), has good chemical, physical, mechanical and thermal characteristics, as well as excellent film-forming abilities, non-toxicity and biodegradability [15-17]. PVA has been utilized in a variety of applications such as sealants, films, coatings, drug carriers, membranes and fuel cells, as well as in the commercial industries, medical and food industries [18-21]. PVA is a water-soluble polymer that may be combined with GO in a homogenous manner in water. As a result, the PVA/GO preparation procedure is reasonably easy and ecologically benign [22]. Furthermore, GO having oxygen-functional groups can affordably and efficiently induce full exfoliation and dispersion of GO homogeneously into the polymer matrices, enhancing the interfacial bond between GO layers and increasing surface sites while also being highly water dispersible. The capacity to accomplish complete exfoliation and uniform dispersion of GO in polymer matrices is required for the full use of $\mathrm{GO}$ layers in the applications of polymer nanocomposite [22,23]. Several studies have prepared PVA/GO, with a primary focus on environmental applications $[24,25]$. However, in these studies, the prepared PVA/GO were not used in removing specific radionuclides and exhibited a low removal capacity. However, this study mainly focused on enhancing the PVA/GO removal capacity targeting radionuclides, U(VI) and Th(IV), in addition to improving its stability, water dispersibility, surface functionality and feasibility for potential applications by functionalization with metal oxides.

Nowadays, due to their unique characteristics such as semiconductivity, paramagnetic nature, thermal stability and fluorescence, lanthanide series materials are increasingly used by several researchers in many applications, such as catalysis [26], adsorption [27] and energy storage [28]. Among the lanthanide elements, gadolinium oxide $\left(\mathrm{Gd}_{2} \mathrm{O}_{3}\right)$ is regarded as an important compound in chemical and physical investigations; they are extremely effective supercapacitor catalysts [29], electrochemical sensors [30] and photodegradators [31] and adsorbers $[32,33]$ due to their useful features and special properties, such as semi conductivity, thermal capacity, and low toxicity. These features of $\mathrm{Gd}_{2} \mathrm{O}_{3}$ enable its use as a good candidate for wastewater treatment.

In this work, we developed a simple, effective, and ecofriendly hydrothermal method to produce PVA/GO gadolinium oxide (PGO-Gd). The produced PGO-Gd composites were characterized by Fourier-transform infrared (FTIR) spectroscopy, thermal gravimetric analysis (TGA), scanning electron microscopy (SEM), X-ray diffraction (XRD), FT-Raman spectrum analysis, transmission electron microscopy (TEM), X-ray photoelectron spectroscopy (XPS) and Brunauer, Emmett and Teller (BET) analyses. Other essential parts of the adsorption mechanism, such as equilibrium, kinetics, $\mathrm{pH}$, and thermodynamics, were also investigated, and the information gained from this research will enhance the adsorption process. This investigation clearly demonstrated the adsorption process involving radionuclides. This is the first report of a PVA-GO-modified adsorbent used for radioactive sequestration that we are aware of. Additionally, the prospective applicability and commercial viability of PGO-Gd were investigated by applying it to actual surface water and assessing its reusability. Moreover, the present material shows high removal capacity for radionuclides, and it can be re-used for up to four cycles without losing its removal efficacy of less than $60 \%$. 


\section{Materials and Methods}

\subsection{PGO-Gd Preparation}

GO was developed using a slightly modified Hummer's technique [34]; 100 mg GO were dispersed in $100 \mathrm{~mL}$ water by ultrasonication and $100 \mathrm{mg}$ PVA were dissolved in $50 \mathrm{~mL}$ water while stirring. The mixed GO and PVA solution was then heated to $120{ }^{\circ} \mathrm{C}$ for $5 \mathrm{~h}$ and cooled to $25^{\circ} \mathrm{C}$, and subsequently centrifuged (8000 rpm for $1 \mathrm{~h}$ ). The collected sample was washed with water before drying at $60{ }^{\circ} \mathrm{C}$, and named PGO.

PGO powder $(100 \mathrm{mg})$ was dissolved in $\mathrm{NaOH}$ solution $(6 \mathrm{~g} \mathrm{NaOH}$ in $100 \mathrm{~mL}$ water) and ultrasonicated for $1 \mathrm{~h}$ to produce a clear mixture. $\mathrm{Gd}\left(\mathrm{NO}_{2}\right)_{3}(500 \mathrm{mg})$ was dissolved in $100 \mathrm{~mL}$ of water. The resulting gadolinium salt solution was dropped into the PGO solution while stirring. The reaction mixture was autoclaved at $120^{\circ} \mathrm{C}$. The final product was filtered and washed with water and ethanol before drying at $60{ }^{\circ} \mathrm{C}$ for $12 \mathrm{~h}$. The product was labeled PGO-Gd. The method is schematically shown in Figure 1.

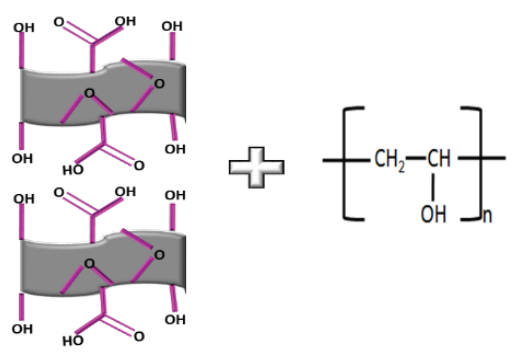

GO
PVA

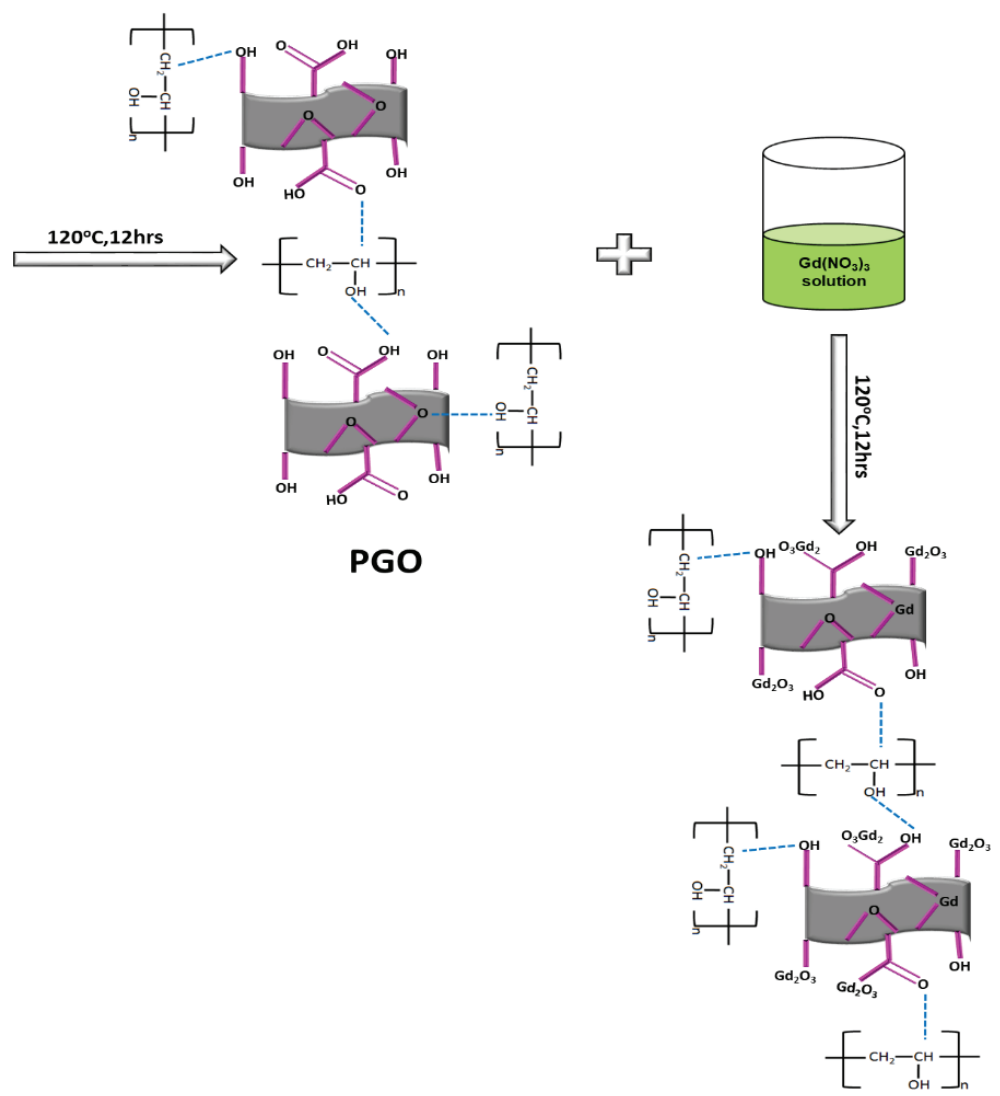

PGO-Gd

Figure 1. Schematic illustration of the method producing PGO-Gd.

\subsection{Removal Studies}

The prepared PGO-Gd was used to sequestration of U(VI) and Th(IV) from water under batch studies. The impact of $\mathrm{pH}$, contact duration, dosage, and metal concentration on U(VI) and Th(IV) adsorption was deliberated. For each batch study, $50 \mathrm{~mL}$ of a known concentration metal solution was placed in a $50 \mathrm{~mL}$ falcon tube and its $\mathrm{pH}$ was regulated to 4.0 before adding $0.1 \mathrm{~g} \mathrm{~L}^{-1}$ PGO-Gd. These tubes were subsequently agitated using a mechanical shaker at room temperature $\left(25 \pm 1^{\circ} \mathrm{C}\right)$ for the prescribed equilibration period. The samples collected from the supernatant solution were separated from the PGO-Gd using $0.45 \mu \mathrm{m}$ filters before being evaluated the concentration of U(VI) and Th(IV) using ICP-OES. At time intervals ranging from 5 to $400 \mathrm{~min}$, the kinetics and effect of contact duration on metal ion sorption were investigated. The sorption isotherms and the impact 
of the metal concentration were studied by changing the initial metal ion concentration from 5 to $100 \mathrm{mg} \mathrm{L}^{-1}$. The $\mathrm{pH}$ impact was examined by changing the solution $\mathrm{pH}$ from 2.0 to 8.0 with a dilute $\mathrm{HCl}$ and $\mathrm{NaOH}$ solutions. All batch studies were conducted in duplicate, and the results shown are the averages of two measurements. The adsorption capacity and \% removal can be calculated based on Equations (1) and (2):

$$
\begin{aligned}
& \text { Adsorption capacity, } q_{e}=\left(C_{o}-C_{e}\right) \times v / m \\
& \text { Adsorption removal } \%=\left(\frac{C_{o}-C_{e}}{C_{o}}\right) \times 100
\end{aligned}
$$

here showing the metal sorption capacity $\left(q_{e}, \mathrm{mg} \mathrm{g}^{-1}\right)$, metal initial and equilibrium concentrations ( $C o$ and $C e, \mathrm{mg} \mathrm{L}^{-1}$ ), volume of solution $(v, \mathrm{~L})$ and adsorbent mass $(m, \mathrm{~g})$.

\subsection{PGO-Gd Regeneration and Application to Surface Water Samples}

The PGO-Gd stability and re-usable feasibility were evaluated through approximately five cycles of reuse. The metal sorption capacity (qe, $\mathrm{mg} \mathrm{g}^{-1}$ ), as shown in Equation (1), was evaluated batch-wise at $\mathrm{pH} 4.0,298 \mathrm{~K}$, and $0.1 \mathrm{~g} \mathrm{~L}^{-1}$ adsorbent to assess the stability of the adsorbent across the cycles.

Surface water was obtained from Seongu-ri, Onjeong-myeon, Uljin-gun and Gyeongsangbuk-do (Republic of Korea) was used for evaluation of prepared material feasible applicability in real system. The specifics are provided in the supplementary material (Supplementary Materials, Table S1). The $\mathrm{pH}$, cations $\left(\mathrm{Ca}^{2+}\right.$ and $\left.\mathrm{Na}^{+}\right)$and anions $\left(\mathrm{PO}_{4}{ }^{3-}, \mathrm{SO}_{4}{ }^{2-}, \mathrm{NO}_{3}{ }^{-}, \mathrm{Cl}^{-}\right.$and $\left.\mathrm{HCO}_{3}{ }^{-}\right)$of the surface water were all measured.

\section{Results and Discussions}

\subsection{PGO-Gd Structural Chracterization}

XPS analysis was used to determine the surface electronic states and compositions of GO and PGO-Gd (Figure 2a). The examined XPS peaks clearly shows C, O and Gd element signal, which are compatible with the EDX findings (Supplementary Materials, Figure S1). In Figure 2a, the peak of C 1s signal is observed at $283.49 \mathrm{eV}$, and the signal at $529.37 \mathrm{eV}$ is attributed to $\mathrm{O}^{2-}$, which corresponds to GO [35]. The Gd 4d XPS plot indicates that the signal at $141.4 \mathrm{eV}$ is attributed with $\mathrm{Gd}^{3+}[36,37]$. Hence, the XPS analysis confirmed the formation of PGO-Gd.
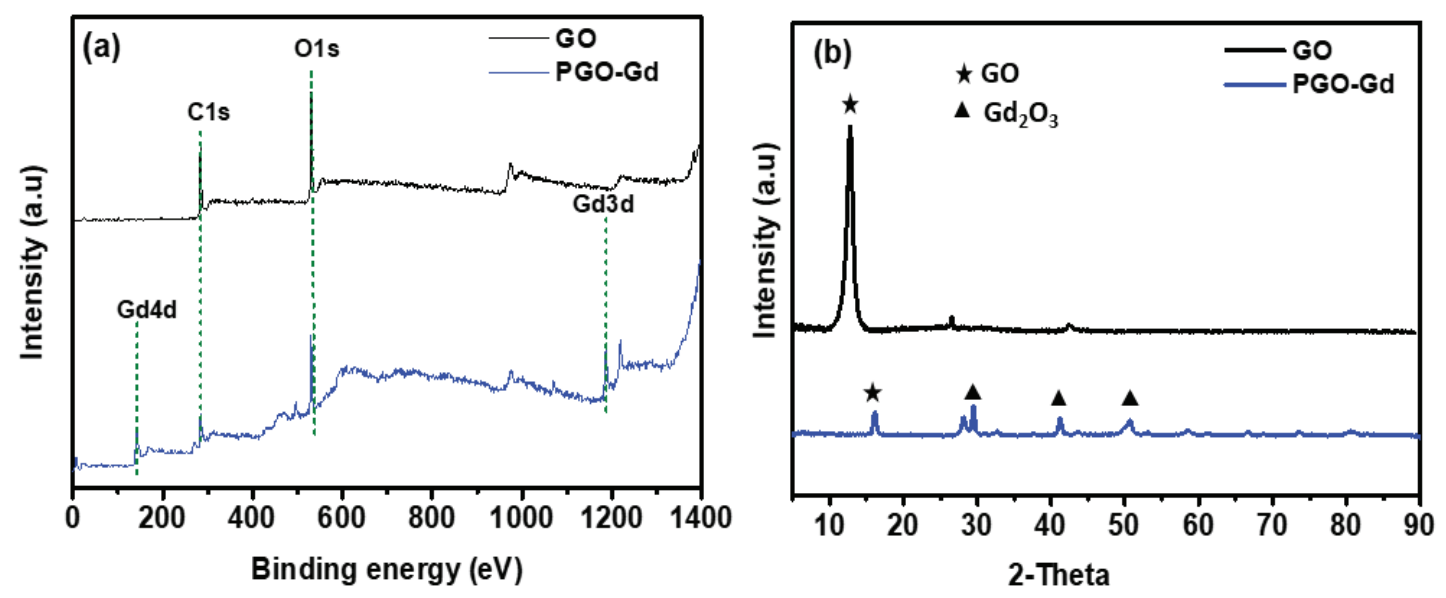

Figure 2. (a) XPS and (b) XRD of GO and PGO-Gd.

The XRD patterns of GO and the PGO-Gd composite are given in Figure 2b. GO shows strong peaks at $2 \theta \approx 11.3^{\circ}$, which corresponds to the (002) planes. The peaks labeled by triangles can be directly indexed to the cubic phase structure of $\mathrm{Gd}_{2} \mathrm{O}_{3}$ (JCPDS no. 12-0797). This indicates the successful integration of $\mathrm{Gd}_{2} \mathrm{O}_{3}$ into PGO [38]. The TGA approach was 
used to measure the amount of oxygenated functionals on the surface of GO and PGO-Gd by oxidative decomposition from $25^{\circ} \mathrm{C}$ to $1200^{\circ} \mathrm{C}$ at a rate of $10^{\circ} \mathrm{C} \mathrm{min}-1$, as illustrated in Figure S1. The resultant TGA plots shows the three phases of the weight decrease in the TGA curves of GO. First, a little mass reduction at below $100{ }^{\circ} \mathrm{C}$ can be due to adsorbed water molecules evaporating. Second, a substantial mass loss from 100 to $350{ }^{\circ} \mathrm{C}$ can be ascribed to the elimination of labile oxygenated functional groups of GO including epoxy, carboxyl, and hydroxyl vapors. Finally, the decomposition of GO caused a modest loss of weight from 350 to $1200{ }^{\circ} \mathrm{C}$. Furthermore, when the GO and PGO-Gd of TGA curves were compared, the weight loss of GO and PGO-Gd at $0-350{ }^{\circ} \mathrm{C}$ were approximately $37 \%$ and $16 \%$, respectively. Hence, both GO and PGO-Gd are presumed to contain an abundance of oxygenated surface functional groups, and that PGO-Gd, some of oxygen-containing groups replaced with $\mathrm{Gd}_{2} \mathrm{O}_{3}$ nanoparticles. At $1200{ }^{\circ} \mathrm{C}$, weight loss for $\mathrm{GO}$ was $\sim 67 \%$, and PGO-Gd was observed $26 \%$, which was related to the formation of cubic $\mathrm{Gd}_{2} \mathrm{O}_{3}$ by the phase transition from hexagonal $\mathrm{Gd}(\mathrm{OH})_{3}$ of $\mathrm{PGO}-\mathrm{Gd}$ [38]. These results suggest a higher stability and surface functionality of PGO-Gd than that of GO.

Figure S2a indicates the FTIR spectra of GO and PGO-Gd. The stretching vibrations of $-\mathrm{OH}\left(3339 \mathrm{~cm}^{-1}\right), \mathrm{C}=\mathrm{C}\left(1634 \mathrm{~cm}^{-1}\right), \mathrm{C}-\mathrm{O}\left(1217 \mathrm{~cm}^{-1}\right)$ and $\mathrm{C}-\mathrm{O}-\mathrm{C}\left(1054 \mathrm{~cm}^{-1}\right)$ were discovered by an FTIR scan of GO. The PGO-Gd spectra displayed stretching vibrations at $3617 \mathrm{~cm}^{-1}(-\mathrm{OH}), 1515 \mathrm{~cm}^{-1}(\mathrm{C}=\mathrm{C}), 1380 \mathrm{~cm}^{-1}(\mathrm{C}-\mathrm{OH})$, and $1217 \mathrm{~cm}^{-1}(\mathrm{C}-\mathrm{O}-\mathrm{H})$ and $\mathrm{Gd}_{2} \mathrm{O}_{3}$ spectra observed $\mathrm{Gd}-\mathrm{O}$ stretching $\left(514 \mathrm{~cm}^{-1}\right)$, and this is consistent with prior results [36]. Furthermore, the strong stretching peak at $710 \mathrm{~cm}^{-1}$ indicates $\mathrm{Gd}(\mathrm{OH})_{3}[39]$. Raman investigation confirmed the existence of substantial GO in the PGO-Gd composite. The Raman spectra of PGO-Gd were compared with those of GO for this purpose, as illustrated in Figure S2b. In general, GO has two major signals in the Raman spectra: the $\mathrm{G}$ and $\mathrm{D}$ bands at 1598 and $1353 \mathrm{~cm}^{-1}$, respectively. Chemically decorated $\mathrm{Gd}_{2} \mathrm{O}_{3}$ on the GO lattice surface exhibited a peak shift and appeared in the D-band at $1347 \mathrm{~cm}^{-1}$, and an expanded G-band at $1590 \mathrm{~cm}^{-1}$. A minor difference in the I(D)/I(G) (are the peak intensity ratio of the D- and G-bond) of PGO-Gd (0.93) comparing with that of GO (0.96) suggested that gadolinium oxide particle surface modification changed the in-plane $\mathrm{sp}^{2}$ graphitic domains of GO. These results are comparable to those obtained with GO coupled with metal oxide nanoparticles and biomolecules [40].

The SEM picture of PGO-Gd in Figure 3a,b indicates that the severely aggregated $\mathrm{Gd}_{2} \mathrm{O}_{3}$ nanoparticles are well dispersed over the PGO surface. A strong electrostatic attraction between the PGO and the $\mathrm{Gd}_{2} \mathrm{O}_{3}$ nanoparticles may help to maintain the composite form. This might be due to the PGO's active surface area and oxygen moieties being drawn to the $\mathrm{Gd}_{2} \mathrm{O}_{3}$ nanoparticles. The TEM image of PGO-Gd is presented in Figure 3c,d, wherein the aggregated $\mathrm{Gd}_{2} \mathrm{O}_{3}$ particles are distributed on the corrugated thin sheet-like membranous layer of the PGO surface because of the paramagnetic nature of gadolinium. Further the TEM results suggest rod chape cubic crystalline with an average diameter of 30-40 nm and a nearly uniform distribution with less aggregation. As a consequence, the TEM results are compatible with the SEM findings and showed the composite's formation at nano level crystals with rod shape. BET analysis provides further information on the surface area and pore structure, wherein the surface area of PGO-Gd was $85.30 \mathrm{~m}^{2} \mathrm{~g}^{-1}$, and the pore diameter and pore volume were $21.37 \mathrm{~nm}$ and $0.18 \mathrm{~cm}^{3} \mathrm{~g}^{-1}$, respectively. The BET results suggest the prepared crystalline PGO-Gd possesses a mesoporous surface morphology. 


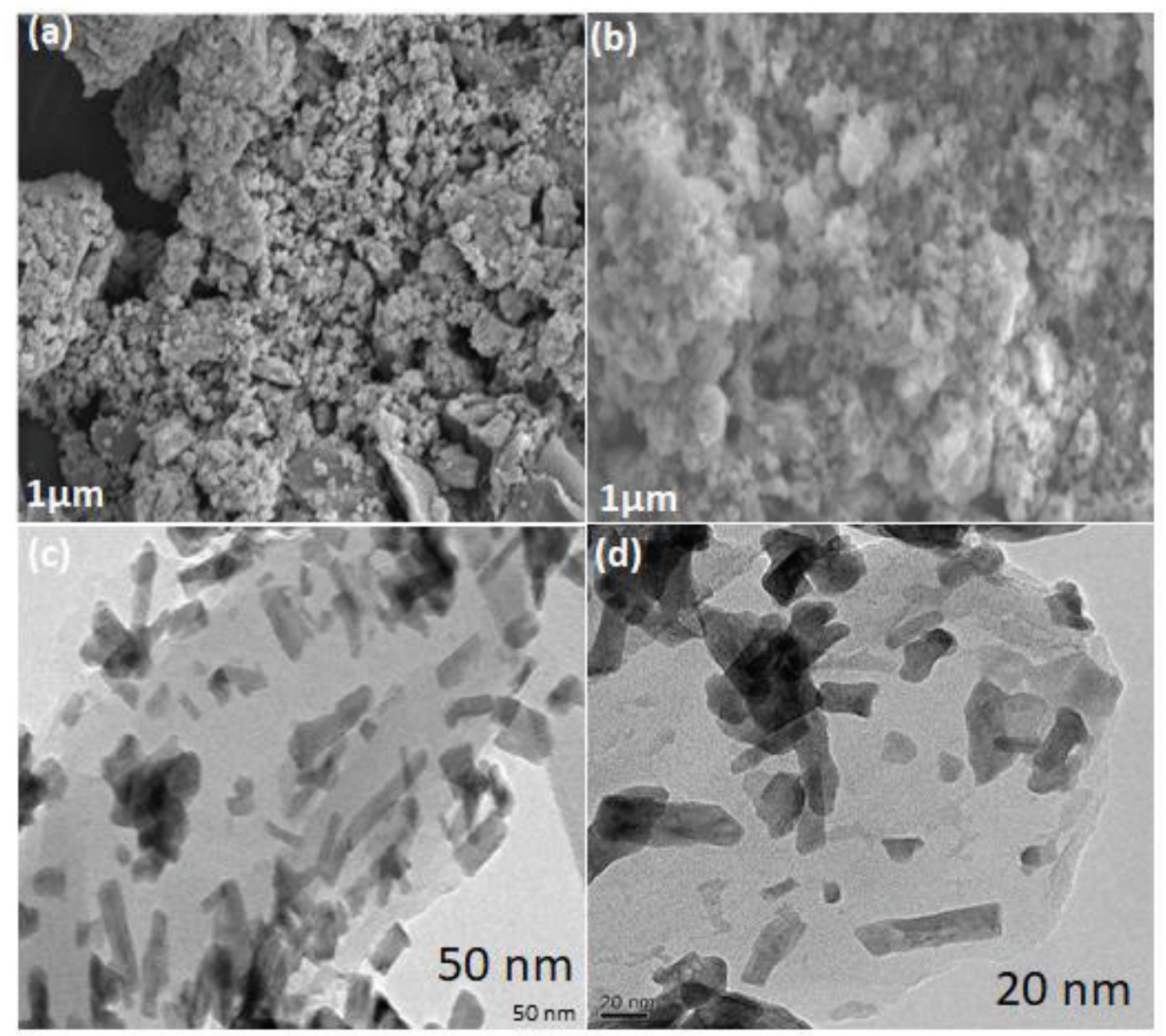

Figure 3. SEM images $(\mathbf{a}, \mathbf{b})$ and TEM images $(\mathbf{c}, \mathbf{d})$ of PGO-Gd.

\section{2. $p H$ Impact on Adsorption}

As given in Figure 4a, the $\mathrm{pH}$ of the aqueous solution considerably affected both radionuclides sorption on to PGO-Gd surface. The adsorption percentages of $\mathrm{U}(\mathrm{VI})$ and $\mathrm{Th}(\mathrm{IV})$ progressively rose in the $\mathrm{pH}$ range of $2.0-4.0$, reaching $99 \%$ at $\mathrm{pH} 4.0$. Upon further increasing the $\mathrm{pH}$ from $4.0-8.0$, the removal percentage remained constant at high values. The increased sequestration of both radionuclides by $\mathrm{PGO}-\mathrm{Gd}$ with solution $\mathrm{pH}$ increases may be ascribed to the PGO-Gd surface charges and dissociation of surface functional groups as well as the dispersion of $\mathrm{U}(\mathrm{VI})$ and Th(IV) species in solution. At $\mathrm{pH}<\mathrm{pH}$ pzc (5.75), PGO-Gd surface pronated (i.e., $\equiv \mathrm{SOH}+\mathrm{H}^{+} \rightarrow \equiv \mathrm{SOH}_{2}{ }^{+}$) and produce positive surface charge. Thus, the small adsorptive efficiency of PGO-Gd is ascribed to the electrostatic repulsion between $\mathrm{U}(\mathrm{VI})$ and $\mathrm{Th}(\mathrm{IV})$ at $\mathrm{pH} 0.5-3.5$, and $\mathrm{UO}_{2} \mathrm{OH}^{+},\left(\mathrm{UO}_{2}\right)_{2}(\mathrm{OH})_{2}{ }^{2+}$, $\left(\mathrm{UO}_{2}\right)_{3}(\mathrm{OH})_{5}{ }^{+},\left(\mathrm{UO}_{2}\right)_{4}(\mathrm{OH})_{7}{ }^{+}, \mathrm{Th}(\mathrm{OH})_{3}{ }^{+}$, and $\mathrm{Th}_{2}(\mathrm{OH})_{2}{ }^{6+}$ at $\mathrm{pH}>4.0[4,9]$, and the positively charged edge functional groups $\left(\mathrm{SOH}_{2}{ }^{+}\right)$on the surface of PGO-Gd. However, due to the deprotonation process (i.e., $\equiv \mathrm{SOH} \rightarrow \equiv \mathrm{SO}^{-}+\mathrm{H}^{+}$) the PGO-Gd surface becomes negatively charged at $\mathrm{pH}>\mathrm{pHpzc}$, which enhances the electrostatic attraction between positive charge ions $\left(\mathrm{U}(\mathrm{VI})\right.$ and Th(IV): $\mathrm{UO}_{2} \mathrm{OH}^{+},\left(\mathrm{UO}_{2}\right)_{2}(\mathrm{OH})_{2}{ }^{2+},\left(\mathrm{UO}_{2}\right)_{3}(\mathrm{OH})_{5}{ }^{+}$, $\left(\mathrm{UO}_{2}\right)_{4}(\mathrm{OH})_{7}{ }^{+}, \mathrm{Th}(\mathrm{OH})^{3+}$, and $\mathrm{Th}_{2}(\mathrm{OH})_{2}{ }^{6+}$ at $\left.\mathrm{pH}>4.0\right)$ and negatively charged $\mathrm{SO}^{-}$groups on PGO-Gd, increasing the proportion of both radionuclides adsorption [4]. This result is further supported by examining the $\mathrm{pH}$ of the treated solution; under acidic conditions, protonation reaction on the surfaces of PGO-Gd slightly increased the solution $\mathrm{pH}$ values, whereas under alkaline conditions, deprotonation reaction on PGO-Gd surface decreased the solution $\mathrm{pH}$ values. Furthermore, at high $\mathrm{pH}$, the dissociation of surface functional groups of PGO-Gd leads to the formation of more negatively charged surface sites that facilitate the binding of $\mathrm{U}(\mathrm{VI})$ and $\mathrm{Th}(\mathrm{IV})$ ions. The features of $\mathrm{U}(\mathrm{VI})$ and $\mathrm{Th}(\mathrm{IV})$ species that predominate at a given solution $\mathrm{pH}$ may have a significant impact on PGO-Gd removal 
effectiveness for $\mathrm{U}(\mathrm{VI})$ and $\mathrm{Th}(\mathrm{IV})$. The relative distribution of $\mathrm{U}(\mathrm{VI})$ and $\mathrm{Th}(\mathrm{IV})$ species according to hydrolysis constants from prior literature can fairly explain the sorption behavior of U(VI) and Th(IV) [9]. From the results of the overall $\mathrm{pH}$ effect, a $\mathrm{pH}$ of 4.0 was chosen as the optimum condition in the present study.
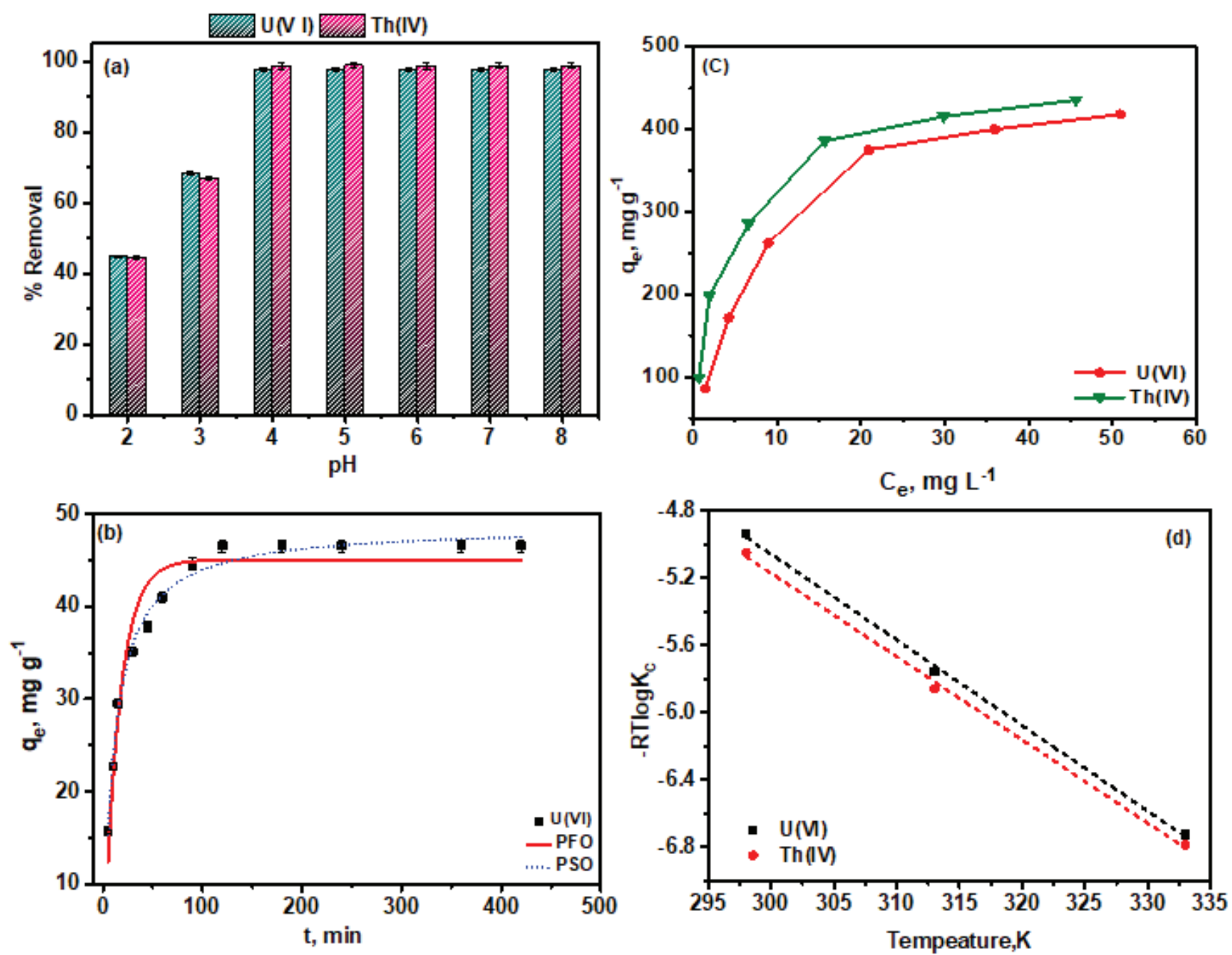

Figure 4. U(VI) and Th(IV) sequestration on PGO-Gd, (a) pH effect, (b) kinetic effect, (c) adsorption isotherms and (d) temperature effect.

\subsection{Kinetics of Adsorption}

The adsorption features of the PGO-Gd adsorbent for radionuclide ions was evaluated by varying the adsorption rate of $\mathrm{U}(\mathrm{VI})$ and $\mathrm{Th}(\mathrm{IV})$ with time. Figure $4 \mathrm{~b}$ presents the results of the kinetic adsorption of $\mathrm{U}(\mathrm{VI})$ and $\mathrm{Th}(\mathrm{IV})$ by $\mathrm{PGO}-\mathrm{Gd}$. The adsorption rate of $\mathrm{U}(\mathrm{VI})$ ions on PGO-Gd increased rapidly during the initial stages of adsorption, reaching approximately $94 \%$ within $60 \mathrm{~min}$ and attained equilibrium within $120 \mathrm{~min}$. Th(IV) adsorptive removal by PGO-Gd was rapid, and 99\% removal occurred within $5 \mathrm{~min}$. The kinetics for the adsorption of $\mathrm{U}(\mathrm{VI})$ and $\mathrm{Th}(\mathrm{IV})$ ions were determined using the following pseudo-first-order (PFO) (Equation (3)) and pseudo-second-order (PSO) (Equation (4)) models:

$$
\begin{aligned}
& \text { PFO kinetic equation : } q_{e}=q_{e}\left(1-10^{-k_{1} \cdot t / 2.303}\right) \\
& \text { PSO kinetic equation : } q_{e}=\left(k_{2} t q_{e}^{2}\right) /\left(1+k_{2} t q_{e}\right)
\end{aligned}
$$

Table 1 lists the adsorbed quantities derived from the kinetic models $\left(q_{e, m o d e l}\right)$, experimental $\left(q_{e, e x p .}\right)$, and other kinetic parameters. The significance of the correlation coefficients $\left(\mathrm{R}^{2}\right)$ was close to 1 , and the closeness of the $q_{e \text { rmodel }}$ and $q_{e, \text { exp }}$. values indicate that the 
adsorption kinetic data of $\mathrm{U}(\mathrm{VI})$ were well explained by PSO model. This results suggest that the U(VI) sorption was rate limits PSO kinetics, whereas, Th(IV) was rapid and was time-independent and have $100 \%$ removal within $5 \mathrm{~min}$.

Table 1. Parameters of PFO and PSO kinetic models for U(VI) sequestration onto PGO-Gd.

\begin{tabular}{|c|c|c|c|c|c|c|}
\hline \multicolumn{3}{|c|}{ PFO } & \multicolumn{3}{|c|}{ PSO } & \multirow{2}{*}{$\mathrm{q}_{\mathrm{e}, \text { exp., }} \mathrm{mg} \mathrm{g}^{-1}$} \\
\hline $\mathrm{q}_{\mathrm{e}, \text { model, }} \mathrm{mg} \mathrm{g}^{-1}$ & $K_{1}$ & $\mathbf{R}^{2}$ & $\mathrm{q}_{\mathrm{e}, \text { model, }} \mathrm{mg} \mathrm{g}^{-1}$ & $\mathrm{~K}_{2}$ & $\mathbf{R}^{2}$ & \\
\hline 38.56 & 0.063 & 0.937 & 44.46 & 0.0019 & 0.991 & 43.25 \\
\hline
\end{tabular}

\subsection{Equilibrium Isotherms}

The maximum adsorption capacity of PGO-Gd for U(VI) and Th(IV) was determined by changing metal ion starting concentrations from 10 to $100 \mathrm{mg} \mathrm{L}^{-1}$ while keeping all other parameters constant $\left(0.1 \mathrm{~g} \mathrm{~L}^{-1}\right.$ adsorbents, $50 \mathrm{~mL} \mathrm{U}$ (VI) and Th(IV) solution, PGO$\mathrm{Gd} \mathrm{pH}$ at 4.0 and temperature at $25^{\circ} \mathrm{C}$ ). The equilibrium isotherm data of both metal ions were plotted in Figure $4 \mathrm{c}$, and the resultant data were simulated using the Langmuir, Freundlich and Temkin isotherm models (Figure S3) to elucidate the adsorption process. The Langmuir, Freundlich and Temkin isotherm models are expressed in Equation (5), (6) and (7), respectively.

$$
\begin{gathered}
\frac{C_{e}}{q_{e}}=\frac{1}{q_{m} K_{L}}+\frac{C_{e}}{q_{m}} \\
\log q_{e}=\log K_{F}+n^{-1} \log C_{e} \\
q_{e}=B \log K_{T}+B \log C_{e}
\end{gathered}
$$

Table 2 lists the Langmuir, Freundlich and Temkin isotherm parameters determined through the fitting procedure. The Langmuir equation, with a higher correlation coefficient $\left(R^{2}\right)$ of 0.998 , fits the experimental data better than the Freundlich and Temkin models, signifying that the adsorption process was the monolayer on the homogeneous surface of PGO-Gd for both metal ions. The resultant maximal removal capacity of PGO-Gd was found to be 427.50 and $455.0 \mathrm{mg} \mathrm{g}^{-1}$ for $\mathrm{U}(\mathrm{VI})$ and Th(IV), respectively. This high adsorption capacity indicates that PGO-Gd is an effective sorbent in removing $\mathrm{U}(\mathrm{VI})$ and Th(IV). The results suggest that the surface functional groups are presumed to play significant roles in the efficient exclusion of $\mathrm{U}(\mathrm{VI})$ and $\mathrm{Th}(\mathrm{IV})$. However, the higher adsorption capacity of $\mathrm{Th}(\mathrm{VI})$ than $\mathrm{U}(\mathrm{VI})$ is may be due to a difference in the ionic radius, in the pKas and in the speciation's. With increasing ionic radius, the steric crowding on the adsorption surface

\begin{tabular}{|c|c|c|c|c|c|c|c|c|c|c|}
\hline \multirow[b]{2}{*}{$\begin{array}{c}\text { Temperature, } \\
\text { K }\end{array}$} & \multirow[b]{2}{*}{ Metal Ion } & \multicolumn{3}{|c|}{ Langmuir } & \multicolumn{3}{|c|}{ Frendlich } & \multicolumn{3}{|c|}{ Temkin } \\
\hline & & $\underset{\mathrm{mg} \mathrm{g}^{-1}}{\mathrm{q}_{\max ^{\prime \prime}}}$ & $\begin{array}{l}\mathrm{K}_{\mathrm{L},} \mathrm{L} \\
\mathrm{mg}^{-1}\end{array}$ & $\mathbf{R}^{2}$ & $\begin{array}{l}\mathrm{K}_{\mathrm{f}} \mathrm{mg} \mathrm{g}^{-1} \\
\left(\mathrm{~L} \mathrm{mg}^{-1) 1 / n}\right.\end{array}$ & $\mathbf{n}$ & $\mathbf{R}^{2}$ & $\mathrm{~B}, \mathrm{~g} \mathrm{~L}^{-1}$ & $\begin{array}{l}\mathrm{K}_{\mathrm{t}}, \mathrm{L} \\
\mathrm{mg}^{-1}\end{array}$ & $\mathbf{R}^{2}$ \\
\hline \multirow{2}{*}{298} & $\mathrm{U}(\mathrm{VI})$ & 427.50 & 0.22 & 0.999 & 132.56 & 3.02 & 0.902 & 188.11 & 5.26 & 0.955 \\
\hline & Th(IV) & 455.00 & 0.24 & 0.998 & 154.25 & 3.25 & 0.896 & 219.04 & 1.77 & 0.971 \\
\hline \multirow{2}{*}{313} & $\mathrm{U}(\mathrm{VI})$ & 465.23 & 0.35 & 0.999 & 141.56 & 2.89 & 0.845 & 199.45 & 4.49 & 0.925 \\
\hline & Th(IV) & 469.67 & 0.38 & 0.997 & 163.25 & 3.12 & 0.912 & 259.58 & 2.18 & 0.976 \\
\hline \multirow{2}{*}{333} & $\mathrm{U}(\mathrm{VI})$ & 479.20 & 0.56 & 0.997 & 150.23 & 2.75 & 0.897 & 205.27 & 5.04 & 0.964 \\
\hline & Th(IV) & 487.56 & 0.49 & 0.995 & 174.36 & 2.95 & 0.876 & 287.80 & 3.76 & 0.965 \\
\hline
\end{tabular}
will also increase; thus, a saturation limit of adsorption is rapidly attained.

Table 2. Parameters of the Langmuir and Freundlich isotherms for U (VI) and Th(IV) removal by PGO-Gd.

The effect of temperature on $\mathrm{U}(\mathrm{VI})$ and Th(IV) adsorption by PGO-Gd was determined by conducting adsorption experiments at 298,313 , and $333 \mathrm{~K}$. With increasing temperature, the sorption efficiency of both metal ions increased, suggesting that the adsorption process 
is endothermic. The slope and intercept of the plot of $\ln K c$ vs. $T$ (Figure $4 \mathrm{~d}$ ) revealed the standard enthalpy change $\left(\Delta \mathrm{H}^{0}\right)$ and entropy change $\left(\Delta \mathrm{S}^{0}\right)$, respectively, and the Van't Hoff equation revealed the Gibbs free energy change $\left(\Delta G^{0}\right)$ and was listed in Table S2. The resultant negative $\Delta \mathrm{G}^{0}$, and positive $\Delta \mathrm{H}^{0}$ and $\Delta \mathrm{S}^{0}$ indicate the feasibility of adsorption However, the fact that adsorption capacities increase with temperature suggests that chemical interactions between the metal ions and PGO-Gd are the primary determinant of both radionuclide adsorptive removal $[4,41]$.

\subsection{Comparison of Adsorption Capacities and Cost}

Table 3 compares the Langmuir $\mathrm{qmax}_{\max }$ of PGO-Gd for U(VI) $\left(427.50 \mathrm{mg} \mathrm{g}^{-1}\right)$ and Th(IV) $\left(455.0 \mathrm{mg} \mathrm{g}^{-1}\right)$ removal with those of other possible adsorbents described in the literature. The qmax of PGO-Gd for both metal ions were equivalent to and somewhat higher than that of numerous other adsorbents described in the literature, according to Table 3 . In addition, the adsorbent PGO-Gd was produced in this work using a simple hydrothermal technique and was recyclable or reusable for more than four cycles (Figure S4) without reducing its original efficacy and stability. As a result, when compared with other adsorbents reported in the literature, the PGO-Gd cost is expected to be low. Furthermore, the cost, stability, and adaptability of the adsorbent employed determine the effectiveness of any adsorption method in water treatment. As a result, the material developed in this work has the ability to effectively treat water polluted with $\mathrm{U}(\mathrm{VI})$ and $\mathrm{Th}(\mathrm{IV})$.

Table 3. Comparison of removal of efficacy of PGO-Gd for U(VI) and Th(IV) using materials reported in the previous literature.

\begin{tabular}{|c|c|c|c|c|}
\hline \multirow{2}{*}{ Absorbent } & \multirow{2}{*}{$\begin{array}{c}\text { Experimental Conditions } \\
\text { Initial Con } \mathrm{mg} \mathrm{L}^{-1} \\
\text { Dosage } \mathrm{mg} \mathrm{L}^{-1} \text { and } \mathrm{pH}\end{array}$} & \multicolumn{2}{|c|}{$\underset{\operatorname{mg~g}^{-1}}{\mathrm{q}_{\max }}$} & \multirow{2}{*}{ Ref. } \\
\hline & & $\mathrm{U}(\mathrm{VI})$ & Th(IV) & \\
\hline $\begin{array}{l}\text { Reduced graphene oxide based } \\
\text { inverse spinel nickel ferrite } \\
\text { (rGONF) }\end{array}$ & $2-30,0.3$ and 3.5 & 200 & 126.58 & [4] \\
\hline $\begin{array}{c}\text { Magnetized watermelon rind } \\
\text { biochar (MWBC) }\end{array}$ & $10-200,0.2$ and 4 & 233.56 & - & [42] \\
\hline $\begin{array}{c}\text { Sugar-based magnetic graphene } \\
\text { oxide (SMGO) }\end{array}$ & $2-30,1.0$ and 4 & 28.2 & - & [43] \\
\hline $\begin{array}{c}\text { Three-dimensional layered double } \\
\text { hydroxide/graphene hybrid } \\
\text { material }\end{array}$ & $20-130,0.01$ and 4 & 277.8 & - & {$[44]$} \\
\hline Gum-g-poly(AAm) composite & $25-1000,0.05$ and 6 & 367.65 & 125.95 & {$[45]$} \\
\hline $\begin{array}{c}\mathrm{PVA} / \mathrm{Fe}_{3} \mathrm{O}_{4} / \mathrm{SiO}_{2} / \mathrm{APTES} \\
\text { nanohybrid }\end{array}$ & $30-500,1.0$ and 5 & - & 112.4 & [46] \\
\hline PVA/TiO2/TMPTMS nanofiber & $30-500,1.0$ and 5 & 187.6 & 222.2 & [47] \\
\hline PGO-Gd & $10-100,0.1$ and 4 & 427.50 & 455.0 & This work \\
\hline PGO & $10-100,0.1$ and 4 & 105.65 & 125.00 & This work \\
\hline
\end{tabular}

\subsection{Adsorption Mechanism}

The use of XPS characterizations aids in understanding the roles of different surface functional groups of PGO-Gd in the adsorption of $\mathrm{U}(\mathrm{VI})$ and $\mathrm{Th}(\mathrm{IV})$. As shown in Figure $5 \mathrm{a}-\mathrm{c}$, the characteristic peaks of the XPS full survey, $\mathrm{C} 1 \mathrm{~s}$ and $\mathrm{O} 1 \mathrm{~s}$, respectively, can be observed in PGO-Gd before and after adsorption. After $\mathrm{U}(\mathrm{VI})$ adsorption, the double characteristic peaks of $\mathrm{U} 4 \mathrm{f}$ and $\mathrm{Th} 4 \mathrm{f}$ appeared in the sample spectra, suggesting effective immobilization of $\mathrm{U}(\mathrm{VI})$ and $\mathrm{Th}(\mathrm{IV})$ on the adsorbent. The high resolution C1s spectra (Figure $5 \mathrm{~b}$ ) was well resolved by three peaks located at $283.31 \mathrm{eV}(\mathrm{C}=\mathrm{C}$ or $\mathrm{C}-\mathrm{C}), 284.96 \mathrm{eV}(\mathrm{C}-\mathrm{OH})$, and $287.35 \mathrm{eV}$ 
$(\mathrm{C}=\mathrm{O})$. The high resolution O1s spectra (Figure $5 \mathrm{c}$ ) was fully resolved into three separate component peaks located at $531.49(\mathrm{C}=\mathrm{O})$ and $529.87(\mathrm{O}=\mathrm{C}-\mathrm{OH})$. Adsorption of metal ions altered the $\mathrm{C} 1 \mathrm{~s}(\mathrm{C}=\mathrm{C}, \mathrm{C}-\mathrm{OH}$, and $\mathrm{C}=\mathrm{O})$ and $\mathrm{O} 1 \mathrm{~s}(\mathrm{C}=\mathrm{O}$ and $\mathrm{O}=\mathrm{C}-\mathrm{OH})$ peak positions, suggesting that $\mathrm{U}(\mathrm{VI})$ was predominantly adsorbed by interacting with $\mathrm{PGO}-\mathrm{Gd}$ surface functional groups such as $\mathrm{C}=\mathrm{C}, \mathrm{C}-\mathrm{OH}$, and $\mathrm{C}=\mathrm{O}$. Moreover, $\mathrm{Th}(\mathrm{IV})$ was predominantly adsorbed by interacting with $\mathrm{PGO}-\mathrm{Gd}$ surface functional groups, such as $\mathrm{C}=\mathrm{C}, \mathrm{C}-\mathrm{OH}, \mathrm{O}=\mathrm{C}-$ $\mathrm{OH}$, and $\mathrm{C}=\mathrm{O}$, which probably contributes to the rapid adsorption of $\mathrm{Th}(\mathrm{IV})$. Furthermore, the adsorption studies, such as $\mathrm{pH}$, kinetics, and isotherms, suggest that both metal ions were adsorbed via electrostatic interactions and surface chemical complexation. However, chemical complexation predominantly influenced the sorption process for both $\mathrm{U}(\mathrm{VI})$ and Th(IV). The plausible sorption mechanism is illustrated in Figure 6.

(a)
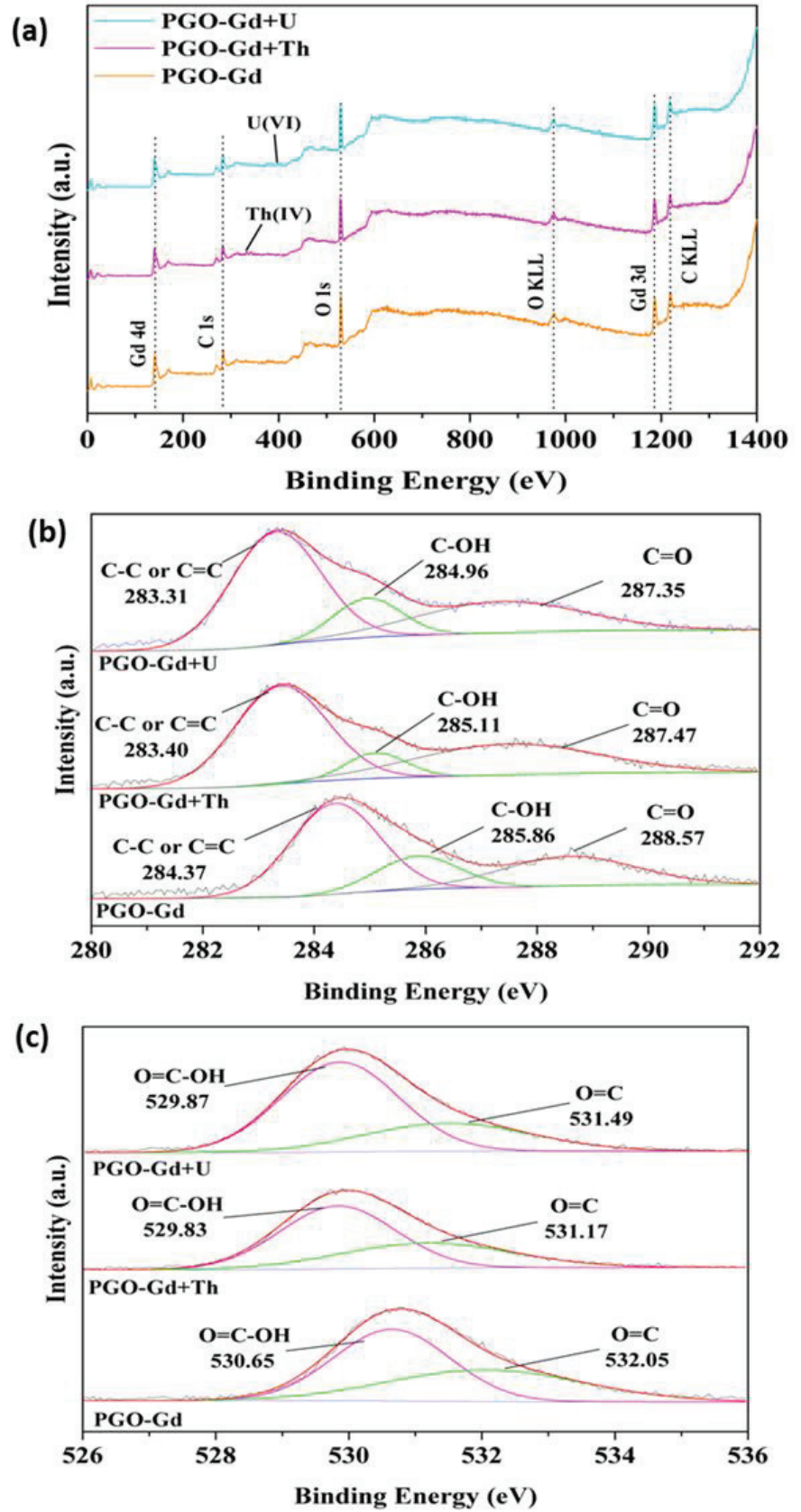

Figure 5. (a) Full XPS spectra of PGO-Gd. High resolution XPS of (b) carbon and (c) oxygen for U (VI) and Th(IV) adsorbed on PGO-Gd. 


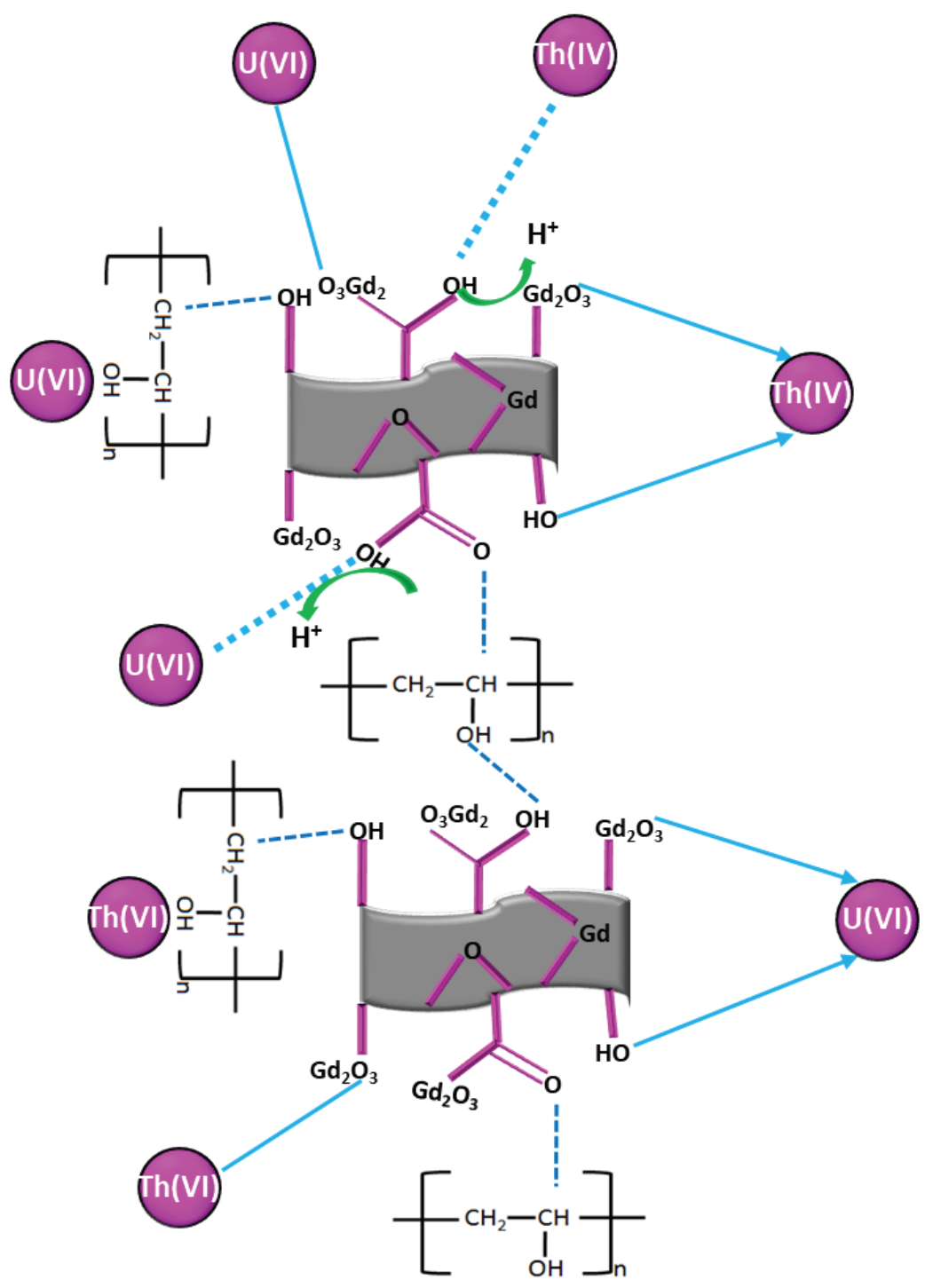

Figure 6. Possibility of U(VI) and Th(IV) adsorption mechanism on PGO-Gd.

\subsection{Studying Environmental Relevance by Treating Metal Spiked Real Surface Water}

Additional studies were performed for evaluating the adsorption stability of PGO-Gd via kinetic experiments to investigate the in-situ applicability for surface water remediation. The stability experiments were performed by adding $0.005 \mathrm{~g}$ of adsorbent to $50 \mathrm{~mL}$ of $10 \mathrm{mg} \mathrm{L}^{-1} \mathrm{U}(\mathrm{VI})$ and $\mathrm{Th}(\mathrm{IV})$-spiked groundwater, and $5 \mathrm{~mL}$ of each supernatant was collected at varying time intervals, filtered, and the residual concentration was estimated by ICP-OES analysis. Compared with U(VI), Th(IV) removal reached the EPA standard level within 5 min (Figure 7), whereas the U(VI) residual concentration in treated water did not reach the EPA standards, indicating the influence of other associate ions, causing lower U(VI) adsorption than that of Th(IV). Moreover, Th(IV) adsorption was unaffected by $\mathrm{U}(\mathrm{VI})$ and vice versa, when the groundwater was spiked with mixed metals (Th(IV) and $\mathrm{U}(\mathrm{VI})$ ) (each contaminated at $10 \mathrm{mg} \mathrm{L}^{-1}$ ). These results suggest the selective sorption of both metal ions under the present experimental conditions. 


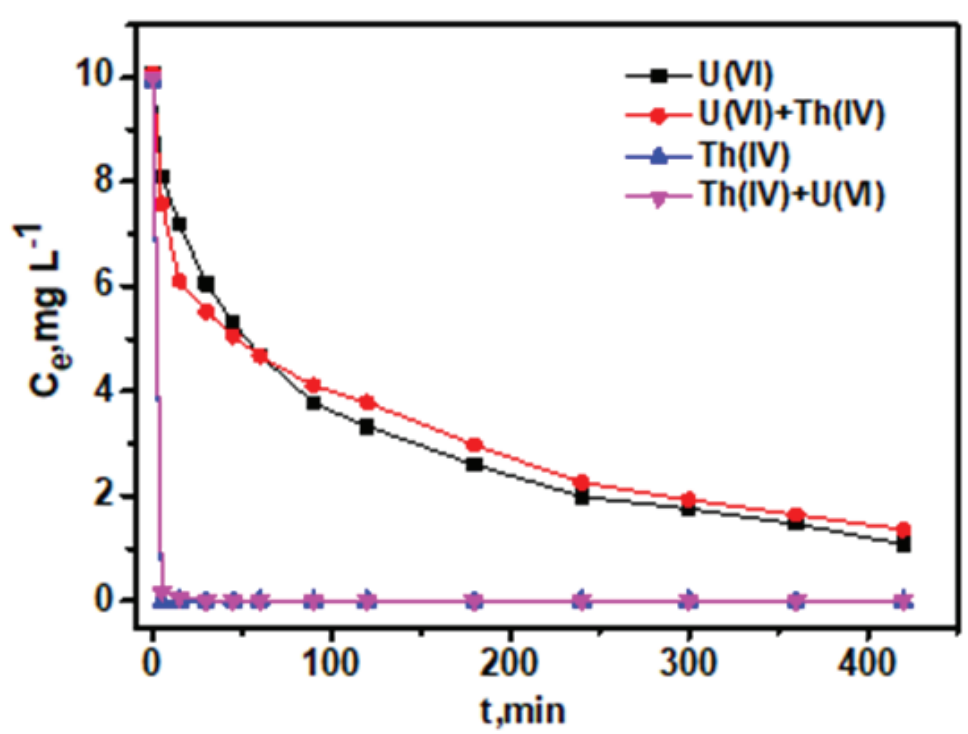

Figure 7. U(VI) and Th(IV)-spiked ground water adsorption kinetic using PGO-Gd.

\section{Conclusions}

In this work, we focused on the facile preparation of PGO-Gd, and studied their sorption mechanism for $\mathrm{U}(\mathrm{VI})$ and $\mathrm{Th}(\mathrm{IV})$ in ground water. Prepared PGO-Gd samples were well characterized by XRD, XPS, FT-IR, Raman and SEM-EDX, which revealed their structure and purity. The sorption characteristics of both metal ions from aqueous solutions were observed under numerous experimental conditions that included $\mathrm{pH}$, kinetic dosage, isotherms, and temperature techniques.

The results are concluded in the following remarks.

(1) Th(IV) and U(VI) absorption was comparably high in PGO-Gd, although Th(IV) adsorption was somewhat greater than U(VI) (VI).

(2) The effect of varied $\mathrm{pH}$ values on metal intake revealed that increasing the $\mathrm{pH}$ enhanced metal ion absorption by PGO-Gd, reaching a maximum at $\mathrm{pH}$ 4.0. This finding also suggests that the surface charge and metal ion species have a significant impact on the adsorbent's sorption capacity.

(3) The $q_{\max }$ of PGO-Gd for U(VI) and Th(IV) was comparable and higher than those of the other absorbents.

(4) The adsorption process is endothermic and thermodynamically favorable.

(5) The PSO kinetic model and the Langmuir isotherm accurately explain the sequestration of U(VI) and Th(IV) by PGO-Gd, suggesting that the rate-limiting monolayer sorption process happened on the PGO-Gd homogeneous surface.

(6) The characterization and adsorption studies concluded that the ions were adsorbed predominantly by surface complexation along with electrostatic interactions through adsorbent surface functionality.

(7) The adsorbent can be reused up to four times without losing its original efficacy or stability. Hence, the use of PGO-Gd to remove radioactive waste from surface water is strongly recommended in this study.

Supplementary Materials: The following are available online at https:/ /www.mdpi.com/article/10 .3390/ polym13213835/s1: Materials and methods, including 1.1. Analytical methods 1.2. Chemicals, and Table S1: Physical and chemical properties of surface water, Figure S1: EDX Spectra of the bare PGO-Gd, Figure S2: Isotherms of U(VI) and Th(IV) onto PGO-Gd $\left(0.1 \mathrm{gL}^{-1}\right.$, pH-4 and initial concentration 10-100 $\mathrm{mg} \mathrm{L}^{-1}$ ), Table S2: Thermodynamic parameters for the U (VI) and Th (IV) on GO-Gd and PGO-Gd at pH 4, Figure S3. Recyclable studies U(VI) and Th(IV) onto PGO-Gd. 
Author Contributions: Conceptualization, formal analysis, methodology, investigation, original draft writing, visualization, L.P.L.; review and editing, validation, M.N.; Supervision and editing, Y.-Y.C.; Designed the Experiments, Investigation, Writing—review and editing, Supervision, J.R.K.; Writing-review and editing, J.-K.Y. All authors have read and agreed to the published version of the manuscript.

Funding: This research received no external funding.

Institutional Review Board Statement: Not applicable.

Informed Consent Statement: Not applicable.

Data Availability Statement: The data presented in this study are available on request from the corresponding author.

Acknowledgments: We acknowledged the National Research Foundation (NRF) of Korea, sponsored by the Ministry of Education (2019R1I1A1A01061487), and the Korea Environmental Industry and Technology Institute (2020002470002) and Research Grant of Kwangwoon University in 2021 for the financial support. Mu. Naushad is grateful to the Researchers Supporting Project number (RSP-2021/8), King Saud University, Riyadh, Saudi Arabia for the financial support.

Conflicts of Interest: The authors indicate that they do not have any known conflicting financial interests or personal ties that might have impacted the work reported in this article.

\section{References}

1. Akkaya, R. Uranium and thorium adsorption from aqueous solution using a novel polyhydroxyethylmethacrylate-pumice composite. J. Environ. Radioact. 2013, 120, 58-63. [CrossRef]

2. Xiao, J.; Chen, Y.; Zhao, W.; Xu, J. Sorption behavior of U(VI) onto Chinese bentonite: Effect of $\mathrm{pH}$, ionic strength, temperature and humic acid. J. Mol. Liq. 2013, 188, 178-185. [CrossRef]

3. Misaelides, P.; Godelitsas, A.; Filippidis, A.; Charistos, D.; Anousis, I. Thorium and uranium uptake by natural zeolitic materials. Sci. Total Environ. 1995, 173, 237-246. [CrossRef]

4. $\quad$ Lingamdinne, L.P.; Choi, Y.L.; Kim, I.S.; Yang, J.K.; Koduru, J.R.; Chang, Y.Y. Preparation and characterization of porous reduced graphene oxide based inverse spinel nickel ferrite nanocomposite for adsorption removal of radionuclides. J. Hazard. Mat. 2017, 326, 145-156. [CrossRef]

5. Alam, A.; Moussa, M. Preparation of graphene/poly(vinyl alcohol) composite hydrogel films with enhanced electrical and mechanical properties. Polym. Compos. 2020, 41, 809-816. [CrossRef]

6. Lingamdinne, L.P.; Koduru, J.R.; Choi, Y.L.; Chang, Y.Y.; Yang, J.K. Studies on removal of Pb(II) and Cr(III) using graphene oxide based inverse spinel nickel ferrite nano-composite as sorbent. Hydrometallurgy 2016, 165, 64-72. [CrossRef]

7. Rouholah, Z.D.; Somayeh, M.F.; Ahmad, B.; Azadeh, T. Highly efficient simultaneous ultrasonic-assisted adsorption of Pb(II), $\mathrm{Cd}(\mathrm{II}), \mathrm{Ni}(\mathrm{II})$ and $\mathrm{Cu}(\mathrm{II})$ ions from aqueous solutions by graphene oxide modified with 2,2'-dipyridylamine: Central composite design optimization. Ultrason. Sonochem. 2016, 32, 265-276. [CrossRef]

8. Lingamdinne, L.P.; Choi, Y.L.; Kim, I.S.; Chang, Y.Y.; Koduru, J.R.; Yang, J.K. Porous graphene oxide based inverse spinel nickel ferrite nanocomposites for the enhanced adsorption removal of arsenic. RSC Adv. 2016, 6, 73776-73789. [CrossRef]

9. Balasubramani, K.; Sivarajasekar, N.; Naushad, M. Effective adsorption of antidiabetic pharmaceutical (metformin) from aqueous medium using graphene oxide nanoparticles: Equilibrium and statistical modelling. J. Mol. Liq. 2020, 301, 112426. [CrossRef]

10. Lingamdinne, L.P.; Koduru, J.R.; Karri, R.R. A comprehensive review of applications of magnetic graphene oxide-based nanocomposites for sustainable water purification. J. Environ. Manag. 2019, 231, 622-634. [CrossRef]

11. Serrano-Garcia, W.; Jayathilaka, W.A.D.M.; Chinnappan, A.; Tran, T.Q.; Baskar, C.; Thomas, S.W.; Ramakrishna, S. Nanocomposites for electronic applications that can be embedded for textiles and wearables. Sci. China Tech. Sci. 2019, 62, 895-902. [CrossRef]

12. Tran, T.Q.; Lee, J.K.Y.; Chinnappan, A.; Loc, N.H.; Tran, L.T.; Ji, D.; Jayathilaka, W.A.D.M.; Kumar, V.V.; Ramakrishna, S. High-performance carbon fiber/gold/copper composite wires for lightweight electrical cables. J. Mater. Sci. Technol. 2020, 42, 46-53. [CrossRef]

13. Stankovich, S.; Dikin, D.A.; Dommett, G.H.B.; Kohlhaas, K.M.; Zimney, E.J.; Stach, E.A.; Piner, R.D.; Nguyen, S.B.T.; Ruoff, R.S. Graphene-based composite materials. Nature 2006, 442, 282-286. [CrossRef] [PubMed]

14. Cobos, M.; Fernández, M.J.; Fernández, M.D. Graphene based poly(vinyl alcohol) nanocomposites prepared by in situ green reduction of graphene oxide by ascorbic acid: Influence of graphene content and glycerol plasticizer on properties. Nanomaterials 2018, 8, 1013. [CrossRef]

15. Finch, C.A. (Ed.) Poly(Vinyl Alcohol): Properties and Applications; John Wiley \& Sons: London, UK, 1973; ISBN 047125892X 9780471258926.

16. Chiellini, E.; Corti, A.; D'Antone, S.; Solaro, R. Biodegradation of poly(vinyl alcohol) based materials. Prog. Polym. Sci. 2003, 28, 963-1014. [CrossRef] 
17. DeMerlis, C.C.; Schoneker, D.R. Review of the oral toxicity of polyvinyl alcohol (PVA). Food Chem. Toxicol. 2003, 41, 319-326. [CrossRef]

18. Mohsen-Nia, M.; Modarress, H. Viscometric study of aqueous poly(vinyl alcohol) (PVA) solutions as a binder in adhesive formulations. J. Adhes. Sci. Technol. 2006, 20, 1273-1280. [CrossRef]

19. Paradossi, G.; Cavalieri, F.; Chiessi, E.; Spagnoli, C.; Cowman, M.K. Poly(vinyl alcohol) as versatile biomaterial for potential biomedical applications. J. Mater. Sci. Mater. Med. 2003, 14, 687-691. [CrossRef]

20. Musetti, A.; Paderni, K.; Fabbri, P.; Pulvirenti, A.; Al-Moghazy, M.; Fava, P. Poly(vinyl alcohol)-based film potentially suitable for antimicrobial packaging applications. J. Food Sci. 2014, 79, E577-E582. [CrossRef]

21. Hyon, S.H.; Cha, W.I.; Ikada, Y.; Kita, M.; Ogura, Y.; Honda, Y. Poly(vinyl alcohol) hydrogels as soft contact lens material. J. Biomater. Sci. Polym. Ed. 1994, 5, 397-406. [CrossRef] [PubMed]

22. Huang, H.D.; Ren, P.G.; Chen, J.; Zhang, W.Q.; Ji, X.; Li, Z.M. High barrier graphene oxide nanosheet/poly(vinyl alcohol) nanocomposite films. J. Membr. Sci. 2012, 409, 156-163. [CrossRef]

23. Deshmukh, K.; Ahamed, M.B.; Deshmukh, R.R.; Khadheer Pasha, S.K.; Sadasivuni, K.K.; Ponnamma, D.L.; Chidambaram, K. Synergistic effect of vanadium pentoxide and graphene oxide in polyvinyl alcohol for energy storage application. Eur. Polym. J. 2016, 76, 14-27. [CrossRef]

24. Xiao, J.; Zhang, J.; Lv, W.; Song, Y.; Zheng, Q. Multifunctional graphene/poly(vinyl alcohol) aerogels: In situ hydrothermal preparation and applications in broad-spectrum adsorption for dyes and oils. Carbon 2017, 123, 354-363. [CrossRef]

25. Dai, J.; Huang, T.; Tian, S.Q.; Xiao, Y.J.; Yang, J.H.; Zhang, N.; Wang, Y.; Zhou, Z. High structure stability and outstanding adsorption performance of graphene oxide aerogel supported by polyvinyl alcohol for wastewater treatment. Mater. Des. 2016, 107, 187-197. [CrossRef]

26. Sharma, G.; Dionysiou, D.D.; Sharma, S.; Kumar, A.; Al-Muhtaseb, A.H.; Naushad, M.; Stadeler, F.J. Highly efficient $\mathrm{Sr} / \mathrm{Ce} /$ activated carbon bimetallic nanocomposite for photoinduced degradation of rhodamine B. Cat. Today 2019, 335, 437-451. [CrossRef]

27. Lingamdinne, L.P.; Koduru, J.R.; Chang, Y.Y.; Kang, S.; Yang, J.K. Facile synthesis of flowered mesoporous graphene oxidelanthanum fluoride nanocomposite for adsorptive removal of arsenic. J. Mol. Liq. 2019, 279, 32-42. [CrossRef]

28. Wu, J.; Fujii, K.; Yashima, M.; Staykov, A.; Akbay, T.; Ishihara, T.; Kilner, J.A. A systematic evaluation of the role of lanthanide elements in functional complex oxides; implications for energy conversion devices. J. Mater. Chem. A 2018, 6, 11819-11829. [CrossRef]

29. Boopathi, G.; Karthikeyan, G.G.; Jaimohan, S.M.; Pandurangan, A.; de Barros, A.L.F.; de Barros, A.L. Dopant effects of Gd ${ }^{3+}$ on the electrochemical pseudocapacitive characteristics of electroactive mesoporous NiO electrodes for supercapacitors. J. Phy. Chem. C 2018, 122, 9257-9274. [CrossRef]

30. Kumar, J.V.; Karthik, R.; Chen, S.M.; Natarajan, K.; Karuppiah, C.; Yang, C.C.; Muthuraj, V. 3D flower-like gadolinium molybdate catalyst for efficient detection and degradation of organophosphate pesticide (fenitrothion). ACS Appl. Mater. Interfaces 2018, 10, 15652-15664. [CrossRef] [PubMed]

31. Mamba, G.; Mbianda, X.Y.; Mishra, A.K.; Mishra, A. Gadolinium nanoparticle-decorated multiwalled carbon nanotube/titania nanocomposites for degradation of methylene blue in water under simulated Solar Light. Environ. Sci. Pollu. Res. 2014, 21, 5597-5609. [CrossRef]

32. Lingamdinne, L.P.; Choi, J.S.; Choi, Y.L.; Chang, Y.Y.; Yang, J.K.; Karri, R.R.; Koduru, J.R. Process modeling and optimization of an iron oxide immobilized graphene oxide gadolinium nanocomposite for arsenic adsorption. J. Mol. Liq. 2020, $299,112261$. [CrossRef]

33. Lee, S.H.; Lingamdinne, L.P.; Yang, J.K.; Chang, Y.Y.; Koduru, J.R. Potential electromagnetic column treatment of heavy metal contaminated water using porous $\mathrm{Gd}_{2} \mathrm{O}_{3}$-doped graphene oxide nanocomposite: Characterization and surface interaction mechanisms. J. Water Process Eng. 2021, 41, 102083. [CrossRef]

34. Hummers, W.S., Jr.; Offeman, R.E. Preparation of graphitic oxide. J. Am. Chem. Soc. 1958, 80, 1339. [CrossRef]

35. Lingamdinne, L.P.; Koduru, J.R.; Roh, H.; Choi, Y.L.; Chang, Y.Y.; Yang, J.K. Adsorption removal of Co(II) from waste-water using graphene oxide. Hydrometallurgy 2016, 165, 90-96. [CrossRef]

36. Prasad, C.V.; Reddy, M.S.P.; Rajagopal Reddy, V.R.; Park, C. Effect of annealing on chemical, structural and electrical properties of $\mathrm{Au} / \mathrm{Gd}_{2} \mathrm{O}_{3} / \mathrm{n}-\mathrm{GaN}$ heterostructure with a high-k rare-earth oxide interlayer. Appl. Surf. Sci. 2018, 427, 670-677. [CrossRef]

37. Lingamdinne, L.P.; Lee, S.; Choi, J.S.; Lebaka, V.R.; Durbaka, V.R.P.; Koduru, J.R. Potential of the magnetic hollow sphere nanocomposite (graphene oxide-gadolinium oxide) for arsenic removal from real field water and antimicrobial applications. J. Hazard. Mater. 2021, 402, 123882. [CrossRef]

38. Qian, B.; Zou, H.; Meng, D.; Zhou, X.; Song, Y.; Zheng, K.; Miao, C.; Sheng, Y. Columnar $\mathrm{Gd}_{2} \mathrm{O}_{3}: \mathrm{Eu}^{3+} / \mathrm{Tb}^{3+}$ phosphors: Preparation, luminescence properties and growth mechanism. CrystEngComm 2018, 20, 7322-7328. [CrossRef]

39. Xu, D.; Zhang, Y.; Zhang, D.; Yang, S. Structural, luminescence and magnetic properties of $\mathrm{Yb}^{3+}-\mathrm{Er}^{3+}$ codoped $\mathrm{Gd}_{2} \mathrm{O}_{3}$ hierarchical architectures. CrystEngComm 2015, 17, 1106-1114. [CrossRef]

40. Veerapandian, M.; Neethirajan, S. Graphene oxide chemically decorated with Ag-Ru/chitosan nanoparticles: Fabrication, electrode processing and immunosensing properties. RSC Adv. 2015, 5, 75015-75024. [CrossRef]

41. Ruyter-Hooley, M.; Larsson, A.C.; Johnson, B.B.; Antzutkin, O.N.; Angove, M.J. Surface complexation modeling of inositol hexaphosphate sorption onto gibbsite. J. Colloid Interface Sci. 2015, 440, 282-291. [CrossRef] 
42. Lingamdinne, L.P.; Choi, J.S.; Angaru, G.K.R.; Karri, R.R.; Yang, J.K.; Chang, Y.Y.; Koduru, J.R. Magnetic-watermelon rinds biochar for uranium-contaminated water treatment using an electromagnetic semi-batch column with removal mechanistic investigations. Chemosphere 2021, 286, 131776. [CrossRef] [PubMed]

43. Choi, Y.L.; Choi, J.S.; Lingamdinne, L.P.; Chang, Y.Y.; Koduru, J.R.; Ha, J.H.; Yang, J.K. Removal of U (VI) by sugar-based magnetic pseudo-graphene oxide and its application to authentic groundwater using electromagnetic system. Environ. Sci. Pollut. Res. 2019, 26, 22323-22337. [CrossRef]

44. Tan, L.; Wang, Y.; Liu, Q.; Wang, J.; Jing, X.; Liu, L.; Liu, J.; Song, D. Enhanced adsorption of uranium (VI) using a three-dimensional layered double hydroxide/graphene hybrid material. Chem. Eng. J. 2015, 259, 752-760. [CrossRef]

45. Shelar-Lohar, G.; Joshi, S. Comparative study of uranium and thorium metal ion adsorption by gum ghatti grafted poly (acrylamide) copolymer composites. RSC Adv. 2019, 9, 41326-41335. [CrossRef]

46. Mirzabe, G.H.; Keshtkar, A.R. Application of response surface methodology for thorium adsorption on $\mathrm{PVA}_{2} / \mathrm{Fe}_{3} \mathrm{O}_{4} / \mathrm{SiO}_{2} / \mathrm{APTES}$ nanohybrid adsorbent. J. Ind. Eng. Chem. 2015, 26, 277-285. [CrossRef]

47. Abbasizadeh, S.; Keshtkar, A.R.; Mousavian, M.A. Preparation of a novel electrospun polyvinyl alcohol/titanium oxide nanofiber adsorbent modified with mercapto groups for uranium (VI) and thorium (IV) removal from aqueous solution. Chem. Eng. J. 2013, 220, 161-171. [CrossRef] 